\title{
МЕТОД УЛУЧШЕНИЯ ПАМЯТИ И ВОСПРИЯТИЯ С ПОМОЩЬЮ МОДЕЛИ, ПОСТРОЕННОЙ НА ОСНОВЕ КОГНИТИВНЫХ СТРАТЕГИЙ ЛЕОНАРДО ДА ВИНЧИ
}

\author{
Шугалей Елена Викторовна, \\ Магистр психологии, Факультет философии Института Профессионального Образования, \\ старший преподаватель Научно-методического центра Фонд интеллектуальных инициатив, \\ г. Санкт-Петербург, Российская Федерачия
}

DOI: https://doi.org/10.31435/rsglobal_ws/31052019/6525

\section{ARTICLE INFO \\ Received: 28 March 2019 \\ Accepted: 15 May 2019 \\ Published: 31 May 2019}

\section{KEYWORDS}

cognitive psychology, cognitive strategies, memory, perception, creativity, neuropsychology, soft skills, Leonardo da Vinci.

\begin{abstract}
The subject of research is the method of implementation a cognitive model for active perception and memory development, and its effectiveness. The model based on Leonardo da Vinci's cognitive strategies was previously constructed, and the method has been worked out for its application.

The relevance of the method was confirmed: the participants increased the speed and depth of their perception, improved short-term, operational and long-term memory. The final measurements showed high dynamic of general intellectual processes and soft skills development, most important for the concept of education in the 21st century.

The study detected the main parameters that increase the perception accuracy and durability of durability of memorization. The methodology, based on model of Leonardo's strategies, helps to develop cognitive and sensory mechanisms, the general dynamics of psychological processes, critical and creative thinking skills, and systematization of information. The application of the method engages the neurophysiological mechanisms of perception.
\end{abstract}

Citation: Shugalei Elena Viktorovna. (2019) Method of Improvement Memory and Perception by the Model Elaborated on Leonardo da Vinci's Cognitive Strategies. World Science. 5(45), Vol.3. doi: 10.31435/rsglobal_ws/31052019/6525

Copyright: (C) 2019 Shugalei Elena Viktorovna. This is an open-access article distributed under the terms of the Creative Commons Attribution License (CC BY). The use, distribution or reproduction in other forums is permitted, provided the original author(s) or licensor are credited and that the original publication in this journal is cited, in accordance with accepted academic practice. No use, distribution or reproduction is permitted which does not comply with these terms.

Введение. Актуальность исследования обусловлена усилением информационного прессинга и развитием инструментальной базы искусственного интеллекта в противовес некоторой механистичности традиционных обучающих программ. С началом Четвертой технологической революции на Всемирном экономическом форуме в Давосе в 2016 году были сформулированы социальные потребности в универсальных навыках XXI века (Soft Skills) и развитии надпрофессиональных компетенций [1]. По исследованиям ЮНЕСКО ключевыми навыками становятся креативность, критическое мышление, умение действовать в неопределенной или проблемной ситуации с множеством исходных параметров, адаптивность, навык кооперации через развитую способность к коммуникации, любопытство и воображение [2]. Ярким носителем универсальной системы компетенций является Леонардо да Винчи, 500-летие памяти которого весь мир отмечает в этом году. Интерес к системе индивидуальных стратегий Леонардо да Винчи обусловлен их востребованностью в современных условиях. Навыки, объясняемые гениальностью, особенностями талантливой личности, закономерно становятся всеобщим достоянием. Основой исследования послужила модель когнитивных стратегий Леонардо да Винчи для развития активного восприятия, укрепления памяти и систематизации информации. Данная модель зарекомендовала себя как действенный практический инструмент для практического овладения этими навыками на основе индивидуальных нейрофизиологических особенностей и социальных 
запросов личности. Методика развивает индивидуальные когнитивные и сенсорные механизмы, качественно усиливает общую динамику психологических процессов. Благодаря активному процессу самоанализа вырабатываются критерии самооценки качества восприятия информации, индивидуальных фильтров восприятия и стратегий прочного запоминания, основанных на нейрофизиологических особенностях.

Целью статьи является анализ действенности методики, основанной на выделенной модели когнитивных стратегий Леонардо да Винчи для выработки личной системы компетенций. Важнейшей целью обучения с помощью разработанной методики является формирование универсальных компетенций, связанных с возрастанием информатизации общества, способности к непрерывному обучению и развитым навыкам системной когнитивной деятельности. В европейском проекте «Определение и отбор ключевых компетенций» (DeSeCo) ключевые компетенции определяются как важные «во мноrих жизненных сферах и служащие залогом жизненного успеха и эффективного функционирования общества» [3]. Исследовались результаты самостоятельного использования методики и возможности применения личных навыков в различных жизненных сферах на основе развития индивидуальных когнитивных нейрофизиологических стратегий.

Предмет и методы исследования. Предметом исследования является результативность методики в активизации восприятия и расширении параметров рабочей памяти по модели когнитивных стратегий Леонардо да Винчи.

В исследовании применялись методы и методики:

1. Теоретические методы:

1.1. Анализ источников, раскрывающих систему когнитивных стратегий Леонардо да Винчи и его работ.

1.2. Анализ психолого-педагогической литературы по проблемам развития памяти и восприятия.

1.3. Моделирование. Смоделирована система компетенций Леонардо да Винчи в области когнитивных стратегий.

1.4. Абстрагирование. На основе наблюдений, сбора статистических данных измерений сформулированы ключевые параметры обучающего методического процесса по стратегии Леонардо да Винчи в различных контекстах и информационных массивах (визуальное, аудиальное, смысловое восприятие объектов и текстов).

2. Эмпирические методы:

1.1. Эксперимент. В ходе практических занятий на протяжении 12 лет автором применялась модель когнитивных стратегий Леонардо да Винчи для развития активного восприятия и памяти. Общее число обученных пользователей методики на авторских курсах - более 1200 человек.

1.2. Измерение и тестирование. Были измерены изменения в скорости восприятия и запоминания различных объектов до и после использования методики в различных временных интервалах. Сравнивалось количество запомненных объектов (см. Рис.2).

1.3. Наблюдение и опрос. Для исследования личной оценки изменений в восприятии и качестве запоминания, автоматического использования методики проведены опросы и собран материал по личной рефлексии.

В ходе исследования проводилось тестирование по методикам: «Изучение зрительной произвольной памяти», оценка ряда из возрастающего числа элементов по методу А. Р. Лурия. Для исследования уровня доступной смысловой организации памяти использовались методы опосредованного запоминания, разработанными Л.С. Выготским, А.Н. Леонтьевым и Л.В. Занковым. Для статистической обработки результатов применялся Т-критерий Вилкоксона.

База исследования: данные получены в ходе обучения 100 слушателей курса по работе с информацией с применением когнитивной стратегии Леонардо да Винчи для активизации восприятия и памяти.

Описание предварительно выделенной модели когнитивных стратегий Леонардо да Винчи в контексте улучшения восприятия и памяти.

Леонардо да Винчи оставил богатый материал для изучения его собственных моделей обучения и работы с информацией. Были изучены первоисточники текстов Леонардо да Винчи и работы других исследователей его творчества. В данной статье цитаты приводятся по источникам $[5,6]$.

Выделены ключевые параметры: 
1. Опора на визуальное восприятие, аналоговый характер которого позволяет неограниченно использовать резервы памяти. Данное положение было доказано экспериментами Ральфа Хабера в 70-х гг. XX в. [4]

Леонардо да Винчи выделял зрение как основной канал получения информации. «Мы ясно знаем, что зрение - это одно из быстрейших действий, какие только существуют; и одной точке оно видит бесконечно много форм и тем не менее понимает сразу лишь один предмет. Предположим случай, что ты, читатель, окидываешь одним взглядом всю эту исписанную страницу, и ты сейчас же выскажешь суждение, что она полна разных букв, но не узнаешь за это время, ни какие именно это буквы, ни что они хотят сказать; поэтому тебе необходимо проследить слово за словом, строку за строкой, если ты хочешь получить знание об этих буквах» [5].

2. Активное восприятие природного объекта. «Картина у живописца будет мало совершенна, если он в качестве вдохновителя берет картины других; если же он будет учиться на предметах природы, то он произведет хороший плод» [5].

3. Припоминание при отсутствии опоры на объект. У Леонардо да Винчи - рисование по памяти. «Все наши знания имеют свои истоки в нашем восприятии» [5].

Леонардо да Винчи развил свою наблюдательность до такой высокой степени, что мог зарисовывать движущиеся турбулентные потоки воды, воздуха (Рис. 2). «Все наши знания имеют свои истоки в нашем восприятии» [5].

4. Уточнение опущенной информации при повторном восприятии объекта до формирования «общего чувства» на основе петель обратной связи, формирующих когнитивную карту воспринимаемого объекта. «Общее чувство выносит суждения о представлениях, полученных от других органов чувств. А эти органы чувств управляются объектами, и объекты посылают свои образы к нашим пяти чувствам, при помощи которых они передаются органу восприятия (imprensiva) и оттуда - общему чувству; и там о них выносятся суждения, после чего они передаются в память, где более или менее четко сохраняются в зависимости от их силы» [6].

5. Обязательное осмысление, формирование «суждения» о воспринятом и запомненном объекте. Запись собственных наблюдений, как это делал Леонардо да Винчи в своих тетрадях. «Хорошее суждение родится от хорошего понимания» [5].

Метод «Leonardo memory skills». Метод разработан и апробирован автором на протяжении более 10 лет занятий в группах по развитию активного восприятия, памяти, динамического чтения, интеллекта и креативности. Обучено более 1200 человек со стойким результатом.

1. Предварительная подготовка и материалы. Знакомство с фактами жизни, иллюстрациями и первоисточниками для создания модели когнитивных стратегий Леонардо да Винчи.

2. Методические пособия. Для тренировки подготовлены: природные материалы (камень, раковина, растения и т.д.), слайды с природными объектами (Рис. 1) и комплект авторских карт с работами Леонардо да Винчи, на обратной стороне для запоминания указаны атрибуты (Рис. 2).

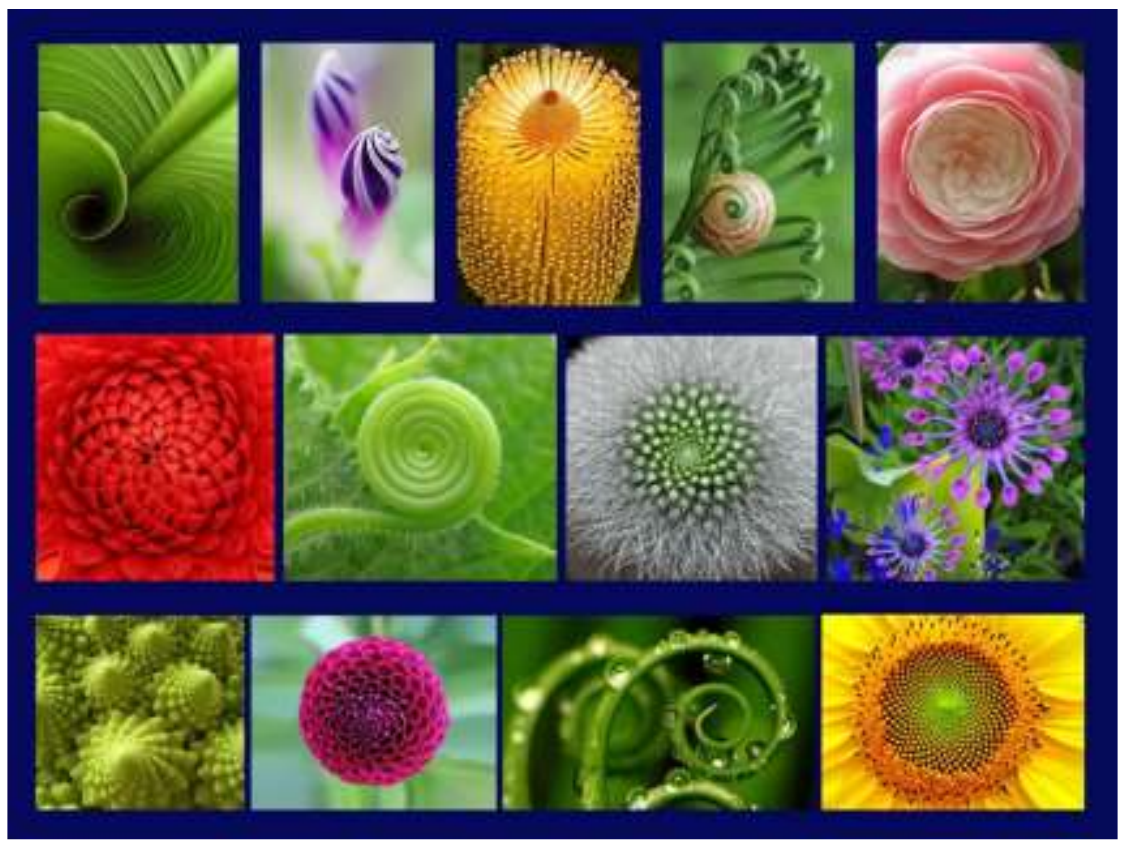

Рис. 1. Пример слайда с природными объектами. 
3. Инструкция-призыв к расслаблению с одновременной максимальной концентрацией внимания. Навык ЕДИНСТВЕННОГО ВЗГЛЯДА. Восприятие объекта ограничено 1-2 сек. В случае слайдов - 2-5 сек. При использовании комплекта методических карт сперва осуществляется тренировка на 1 карте, а затем используется матричный расклад 16 и более карт квадратом (всего 64 карты).

4. Активное припоминание (2-10 сек.) без опоры на объект. Глаза отводятся.

5. Второе предъявление с концентрацией внимания на опущенной информации. Добор информации. Акцент только на том, что не было воспринято - 1-2 сек.

6. Третье предъявление с концентрацией внимания на опущенной информации. Добор информации. Акцент только на том, что не было воспринято, деталях и нюансах - 1-3 сек. Одновременно на примере слайда (Рис. 1) отмечаются особенности собственных фильтров восприятия: какие параметры характеризуют плохо воспринимаемые объекты: выразительность цвета, ассоциативная составляющая, цветовые предпочтения, размер и положение на слайде.

7. Активное припоминание новых параметров $-2-5$ сек.

8. Целостное восприятие объекта и активное припоминание, закрепление. В свободном режиме составляется целостное впечатление и проверяется точность запоминания.

9. Анализ индивидуальных особенностей и фильтров восприятия. Осмысление личной последовательности, стратегии запоминания. Запись в рабочем блокноте результатов и выводов.

10.Припоминание через 20 минут и через 1,5 часа с соответствующим анализом. Оценка фильтров и стратегий оперативной (рабочей) памяти.

11.Проверка качества запоминания и оценка собственных фильтров долговременной памяти через 3 суток.

Осознанный анализ и формирование структурных связей помогает запечатлеть информацию более целостно. В соответствии с исследованиями и выводами Германа Эббингауза подтверждена необходимость интервальных повторений, непродуктивность механической тренировки [7]. Скорость и количество запоминаемых объектов существенно увеличиваются благодаря использованию данной методики.

Для постоянного прогресса обучения рекомендовано увеличение количества предъявляемых объектов, их разнообразия и сложности. Для самостоятельной тренировки можно использовать художественные и видовые альбомы. При использовании карт задание усложняется не только количественно, но и качественно: добавляется запоминание названий, времени создания и места локации источников (атрибутика) на обратной стороне карты.
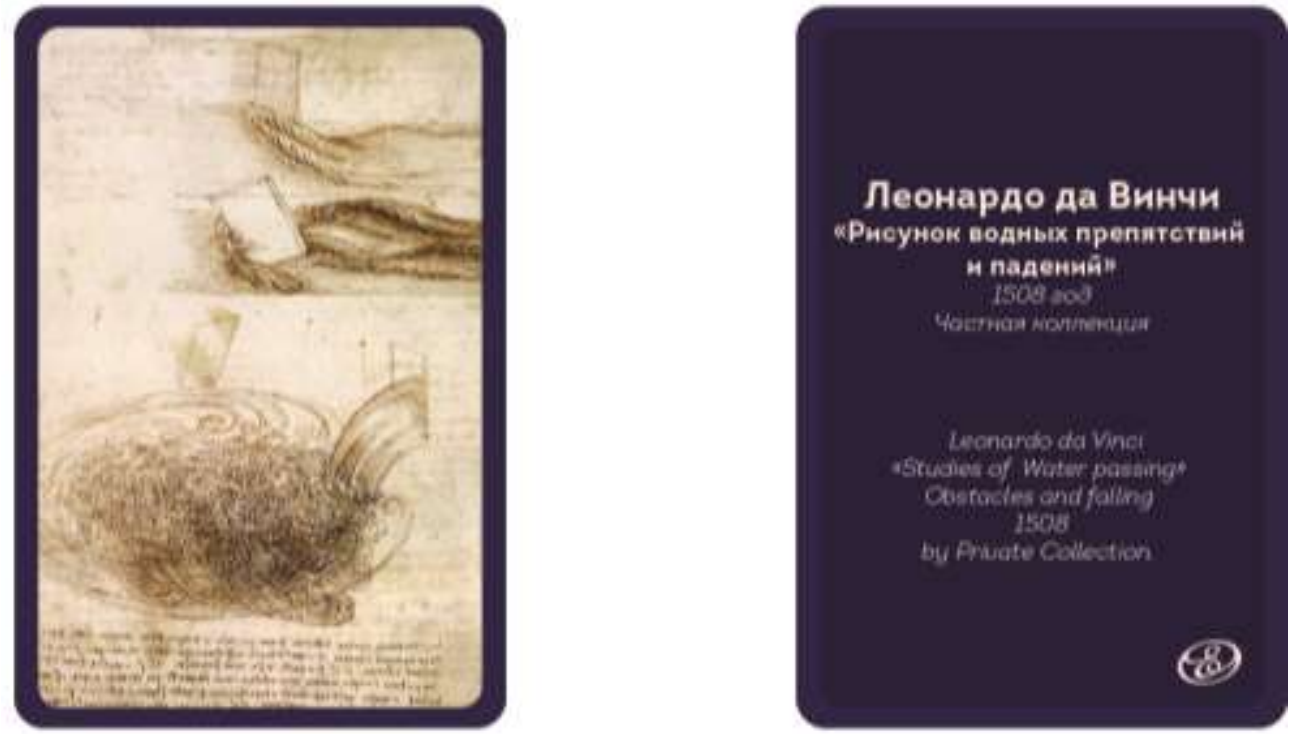

Puc. 2. «Studies of Water passing». Leonardo da Vinci, 1508 by Private Collection.

Результативность методики, выявленная по результатам замеров количества запомненных объектов (100 участников курсов, 2 группы 47 и 53 человека).

Все участники курса продемонстрировали высокий рост показателей запоминания за краткое время предъявления около 20 секунд для количества объектов до 25 и около 2-3 минут для 36-64 объектов. При использовании карт «Leonardo memory skills» и постановке дополнительной цели запоминания названий, данных о произведении время для физического 
расположения карт на поверхности увеличивалось до 10-15 минут, включая процесс запоминания. Замеры производились в течение 3 недель.

Обязательный анализ нейрофизиологически обусловленных личных характеристик фильтров восприятия и стратегий запоминания способствовал результативности. Активизировались механизмы непроизвольного запоминания благодаря осознанному формулированию задач. Как подтверждают экспериментальные исследования А.А. Смирнова и П.И. Зинченко, целеполагание в когнитивной деятельности увеличивает ее эффективность [8].

Слушателями отмечены рост скорости восприятия, его полнота и быстрая обучаемость. Субъективно все участники отмечают повышенный уровень бодрости при высокой скорости упражнений, повышенный уровень концентрации внимания. Одновременно отмечены проявления нейрофизиологического механизма детекции ошибок и автокоррекции стратегий запоминания с акцентом на недостаточно развитых личных позициях.

В процессе тренировок автоматически активизируются когнитивные способности: перцептивная скорость, способности к оперированию пространственными отношениями, процесс индукции, т.е. способность выводить правила, которым подчиняется конкретный набор стимулов. Категоризация и систематизация объектов запоминания становится осознанным фрагментом личной стратегии запоминания.

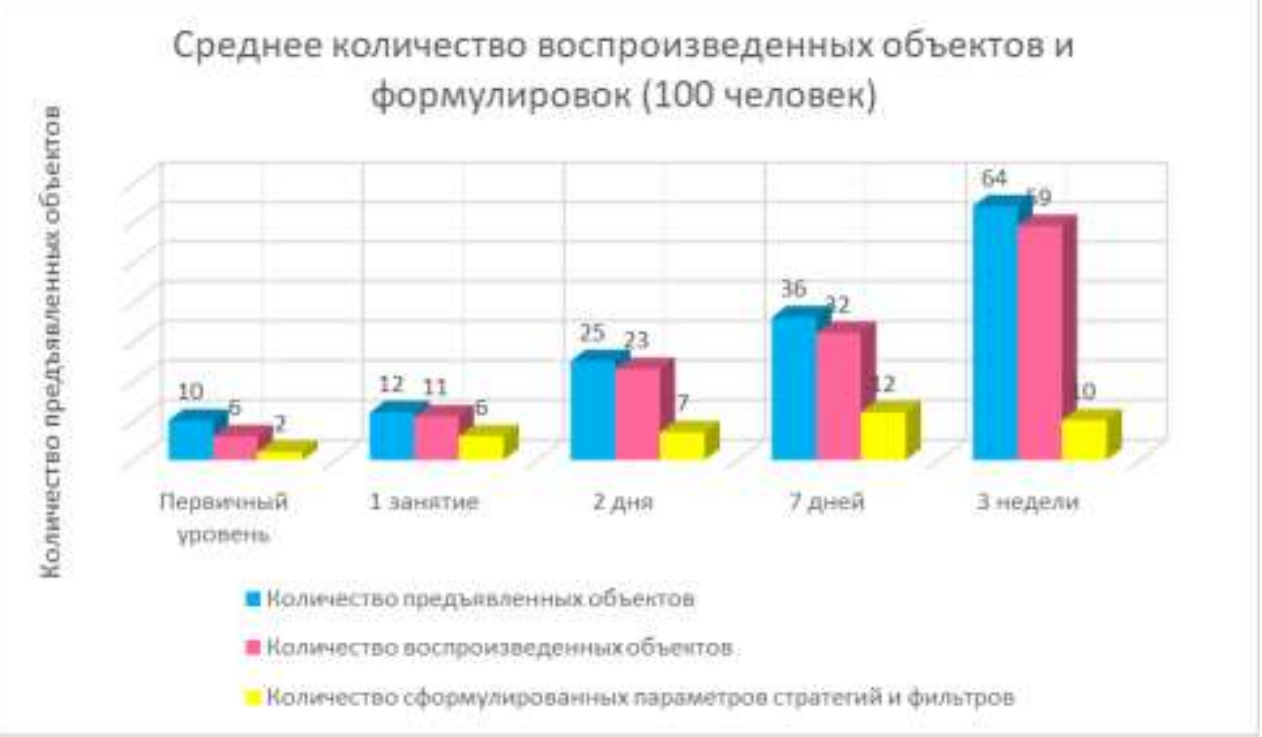

Рис. 3. Результаты диагностики развития памяти по количеству воспроизведенных объектов.

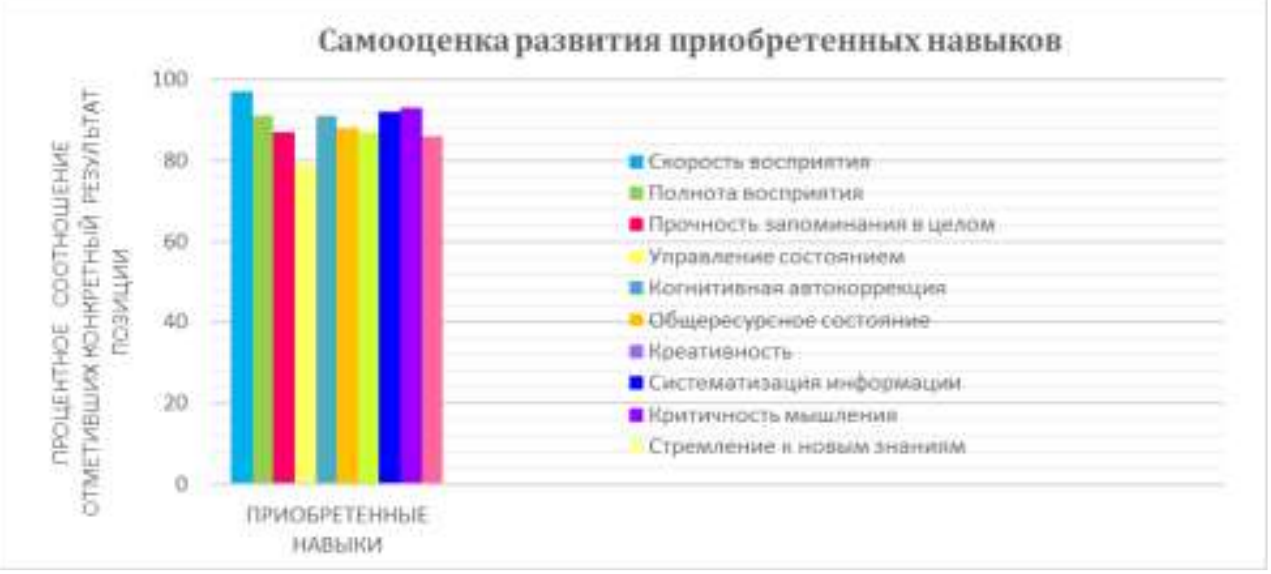

Puс. 4. Результаты опроса о личных результатах после обучения по методике «Lеопагdo memory skills».

Снижение количества формулировок объясняется обобщением и сжатием выводов в самих формулировках. Смысловая память с опорой на динамичное восприятие становится доминирующей формой когнитивного поведения.

Результативность методики, выявленная по результатам опроса 250 участников после завершения курса. Респонденты в произвольной форме ответили на вопросы анкеты 
«Личные изменения в качестве восприятия и памяти после обучения». В опросе принимали участие участники курсов, закончившие обучение более 3 месяцев назад.

Все формулировки были предложены самими респондентами, из них выбраны 10 общих, указанных подавляющим большинством. На диаграмме представлено процентное соотношение выбранных участниками формулировок результатов. Субъективно все участники отмечают подъем настроения, бодрости, удовольствия от результатов и от изменений в восприятии мира в целом. Осознанное управление личными когнитивными процессами дает мощный стимул для непрерывного обучения и развития. «Наслаждение от понимания — самое благородное удовольствие» [6].

Выводы. В исследовании выявлены основные параметры, повышающие скорость восприятия и качество закрепления информации в памяти. Методика на основании модели стратегий Леонардо да Винчи развивает индивидуальные когнитивные и сенсорные механизмы, общую динамику психологических процессов. Активно задействованы нейрофизиологические инструменты восприятия, повышается скорость и прочность запоминания, развиваются навыки систематизации информации, критического и креативного мышления. Параллельно приобретаются осознанные критерии самооценки качества восприятия информации, индивидуальных фильтров восприятия и стратегий прочного запоминания, основанных на нейрофизиологических особенностях.

Личные когнитивные стратегии используются и закрепляются в различных информационных ситуациях. Методика позволяет развивать индивидуальные когнитивные и сенсорные механизмы, естественные встроенные инструменты и закреплять их с помощью когнитивных стратегий, приобретаемых в процессе обучения.

Результативность метода подтверждена полученными данными: увеличение скорости и качества восприятия, расширение параметров кратковременной, оперативной, долговременной памяти, высокая динамика интеллектуальных процессов в целом. Формируется навык регуляции познавательной деятельности и анализа собственных стратегий восприятия и запоминания различных типов информации в разных контекстах (метапамять или знание о самом процессе мышления и запоминания). Эти результаты способствуют развитию гибких навыков, надпрофессиональных компетенции (Soft Skills), востребованных в образовании XXI века.

Методика позволяет формировать устойчивые навыки «4К» (4 C-s): основные универсальные (ключевые) компетенции, необходимые для обучения в современном мире. В них входят: creativity (креативность), critical thinking (критическое мышление), communication (коммуникация), cooperation (кооперация, сотрудничество). Гибкие когнитивные навыки являются компонентами модели навыков XXI века, разработанной Partnership for 21st Century Learning, или Р21) в 2002 году [9].

Социальное значение методики обусловлено влиянием активного восприятия и осознанного использования индивидуальных стратегий памяти на развитие коммуникативных компетенций [10]. Методика актуальна в современных гибких формах непрерывного образования.

\section{ЛИТЕРАТУРА}

1. World Economic Forum. New Vision for Education. Retrieved from http://www3.weforum.org/docs/WE FUSA_NewVisionforEducation_Report2015.pdf

2. UNESCO Digital Library. The Futures of learning 2: what kind of learning for the 21st century? Retrieved from https://unesdoc.unesco.org/ark:/48223/pf0000242996

3. Иванов, Д.А. Компетентности и компетентностный подход в современном образовании / Д.А. Иванов. - М.: Чистые пруды, 2007. - с. 7.

4. Haber R. How We Remember What We See // Scientific American. 1970. May.

5. Леонардо да Винчи. Суждения о науке и искусстве: пер. с итал. / Леонардо да Винчи; предисл. С.М. Даниэль. - СПб.: Азбука-классика, 2001.

6. Леонардо да Винчи. Избранные произведения в 2 т. / Леонардо да Винчи; Пер. А. А. Губера, В. П. Зубова, В. К. Шилейко, А. М. Эфроса; под ред. А. К. Дживелегова, А. М. Эфроса - М.: Изд-во Студии Артемия Лебедева, 2010.

7. Хрестоматия по общей психологии. Психология памяти / Под ред. Ю.Б. Гиппенрейтер, В.Я. Романова. - М.: 1979.

8. Зинченко П.И. Проблема непроизвольного запоминания / Научные записки Харьковского гос. пед. института иностранных языков. Т. 1. - 1939.

9. P21's reports and publications support a vision for learning to ensure 21st century readiness for every student. Retrieved from https://www.teacherrambo.com/file.php/1/21st_century_skills.pdf

10. Психология памяти / Под ред. Ю. Б. Гиппенрейтер, В. Я. Романова. — М.: 1998-2000. 